\title{
ВЫСОКОКАЧЕСТВЕННЫЕ БЕТОНЫ НА ОСНОВЕ ВТОРИЧНОГО СЫРЬЯ В СОВРЕМЕННОМ МОНОЛИТНОМ СТРОИТЕЛЬСТВЕ
}

Муртазаева T.C-A. ${ }^{1,2}$, Аласханов А.X.', Исмаилова 3.X. ${ }^{1}$, Габашев А.А. ${ }^{1}$

${ }^{1}$ ГГНТУ им. акад. М.Д. Миллионщикова, г. Грозный ${ }^{2}$ Академия наук Чеченской Республики, г. Грозный

В работе представлен анализ опыта получения $и$ использования высококачественных бетонов (ВКБ). Изучена природная и техногенная сырьевая база Чеченской Республики и других регионов страны. Приведены результаты испытаний наполненных вяжущих, полученных с использованием продуктов переработки бетонного лома и кирпичного боя. Получены составы ВКБ классов по прочности на сжатие до В80 и изучены их рецептуры и основные реотехнологические и физико-механические свойства.

Ключевые слова: техногенное сырье, высококачественные бетонные смеси, вторичные материалы, наполненное вяжущее, экология, экономия

В настоящее время для возведения конструктивных элементов зданий и сооружений наряду с традиционными бетонами класса B7,5-B30 широкое применение получают новые эффективные бетонные композиты: высокопрочные, безусадочные, расширяющиеся, напрягающие и другие, в том числе на новых композиционных или наполненных вяжущих [1-3].

Ввиду развития высотного монолитного строительства во всем мире наиболее перспективными среди приведенных модифицированных бетонов являются многокомпонентные высококачественные (в том числе и высокопрочные) бетоны, технология получения и свойства которых существенно отличаются от составов и свойств обычных бетонных смесей [4-6].

Анализ опыта получения высокопрочных бетонов показывает, что их получение связано, как правило, использованием высококачественных и, в большинстве случаев, привозных природных сырьевых материалах, что существенно влияет на себестоимость таких бетонов [7-9].

При рациональном подходе с применением современных химических модификаторов структуры бетона, минеральных добавок различной природы, а также эффективного оборудования по активации сырья и гомогенизации смеси, можно рекомендовать составы высокопрочных бетонов на основе местного природного и техногенного сырья.

Большой интерес к использованию вторичного продукта дробления бетонного лома, по мнению авторов работы, вызван возможностью его применения в качестве тонкомолотого минерального компонента в смешанных 
или так называемых наполненных вяжущих, характеризующихся улучшенными технологическими и физико-механическими свойствами, на основе использования которых можно получать высокопрочные бетоны, в том числе и для монолитного высотного строительства [14-16].

В качестве мелкого заполнителя использовался природный песок Червленского месторождения Чеченской Республики со следующими характеристиками: модуль крупности Мк $=1,8-1,9$; пустотность - 40,8 \%; содержание пылевидных и глинистых частиц $-1,7-1,9 \%$; плотность $\rho_{\text {ист. }}=2617$

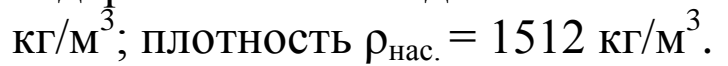

Для обогащения местного песка в отдельных испытаниях применялся природный песок Алагирского месторождения из РСО-Алания со следующими характеристиками: модуль крупности Мк $=2,8-3,2$; пустотность $-44,9$ \%; содержание пылевидных и глинистых частиц $-0,85 \%$; плотность $\rho_{\text {ист }}=2688$ кг $/ \mathrm{M}^{3}$; плотность $\rho_{\text {нас }}=1467 \mathrm{\kappa} \Gamma \mathrm{M}^{3}$.

В качестве крупного заполнителя использовался местный щебень из гравия фракций 5-20 мм с Аргунского и Серноводского месторождений Чеченской Республики и привозной щебень фракции 5-20 мм из гранитнодиабазовых пород Алагирского месторождения РСО-Алания.

В экспериментальных исследованиях использовался бездобавочный портландцемент марки ПЦ 500 Д0 производства ГУП «Чеченцемент» (Чеченская Республика, с. Чири-Юрт) с НГ = 25,5\%, удельной поверхностью $3252 \mathrm{~cm}^{2} / \Gamma$, водоотделением $\leq 18 \%$ и сроками схватывания 2 час. 15 мин. (начало) и 3 час. 40 мин. (конец).

В сравнительных испытаниях применялся «Новоросцемент» марки ПЦ 500 Д0 производства ОАО «Верхнебаканский цементный завод» (г. Новороссийск, п. Верхнебаканский) с НГ = 26,2 \%, удельной поверхностью $3125 \mathrm{~cm}^{2} / \Gamma$, водоотделением 15,6\% и сроками схватывания 2 час. 25 мин. (начало) и 3 час. 45 мин. (конец). Минералогические составы указанных вяжущих следующий:

1. Чеченцемент: $\mathrm{C}_{3} \mathrm{~S}=59 \% ; \mathrm{C}_{2} \mathrm{~S}=16 \% ; \mathrm{C}_{3} \mathrm{~A}=8 \% ; \mathrm{C}_{4} \mathrm{AF}=13 \%$;

2. Новоросцемент: $\mathrm{C}_{3} \mathrm{~S}=61 \% ; \mathrm{C}_{2} \mathrm{~S}=11 \% ; \mathrm{C}_{3} \mathrm{~A}=4 \% ; \mathrm{C}_{4} \mathrm{AF}=13 \%$.

Для обеспечения пластифицирующего эффекта использовались современные добавки строительной химии - суперпластификатор (СП) «Линамикс ПК» и замедлитель твердения «Линамикс РС» на основе полиоксиэтленовых производных полиметакриловой кислоты; гиперпластификатор «MC-PowerFlow» на основе новейшей технологии эфиров поликарбоксилатов MC; CП «Sika ViscoCrete 5-600 SK» на основе поликарбоксилатных эфиров и комплексная полифункциональная добавка «Д5».

Сырьем для получения дисперсных минеральных наполнителей техногенной природы (МНТП) послужили техногенные отходы, а именно бетонный лом и керамический кирпичный бой (ККБ), которые предварительно подвергались механообработке. 
Все МНТП измельчались в течение 5 минут в лабораторной вибрационной шаровой мельнице «МВ-20-ЭКС» с объемом загрузки 5-6 литров до получения удельной поверхности 450-600 м²/кг.

Суперпластификатор «Линамикс ПК» дозировался в бетонных смесях на НВ в количестве от 0,3 до $0,4 \%$ от массы цемента, т.е. в небольшом количестве, поскольку в составе НВ уже есть комплексная модифицирующая добавка Д-5, обладающая пластифицирующими свойствами.

Добавка «Линамикс РС» дозировалась в количестве 0,7 \% от массы цемента и применялся в бетонных смесях повышенной сохраняемости (7-8 часов и более).

Химический состав исходного сырья, а также макро- и микроструктура бетонных образцов исследовались с помощью дисперсионно-энергетического спектрометра (ДЭС) растрового электронного микроскопа Quanta 3D 200i c интегрированной системой микроанализа Genesis Apex 2 EDS от EDAX.

С целью получения оптимальных рецептур высокопрочных бетонов с комплексным использованием местной сырьевой базы, в том числе и техногенной природы, были разработаны составы наполненных вяжущих (НB) с тонкомолотым минеральным наполнителем техногенной природы (МНТП), позволяющих получить высокопрочный цементный камень с заметно меньшими по размеру порами и меньшей усадкой (таблица 1).

Таблица 1 - Свойства НВ с тонкомолотым МНТП

\begin{tabular}{|c|c|c|c|c|c|c|c|}
\hline \multirow{2}{*}{$\begin{array}{c}\text { Наимено- } \\
\text { вание } \\
\text { вяжущего }\end{array}$} & \multirow[t]{2}{*}{$\underset{\%}{\mathrm{H \Gamma},}$} & \multirow{2}{*}{$\begin{array}{c}\mathrm{S}_{\text {уд }} \\
\text { вяжущего, } \\
\mathrm{M}^{2} / \text { кг }\end{array}$} & \multirow{2}{*}{ 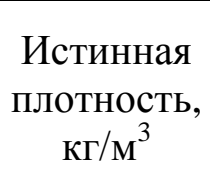 } & \multirow{2}{*}{$\begin{array}{c}\text { Водо- } \\
\text { отде- } \\
\text { ление, \% }\end{array}$} & \multicolumn{2}{|c|}{$\begin{array}{c}\text { Сроки } \\
\text { схватывания, } \\
\text { час. - мин. }\end{array}$} & \multirow{2}{*}{$\begin{array}{c}\text { Актив- } \\
\text { ность, } \\
\text { МПа }\end{array}$} \\
\hline & & & & & начало & конец & \\
\hline HB-75:25 & 17 & 558 & 2986 & 15,5 & $3-40$ & $5-30$ & 71,3 \\
\hline HB-60:40 & 19 & 577 & 2905 & 14,7 & $3-55$ & $5-35$ & 60,7 \\
\hline
\end{tabular}

В связи с тем, что исследования проводились в рамках соглашения о проведении испытаний по определению рецептуры бетонных смесей для возведения подземной части МФК «Ахмат Тауэр», в работе поставлена задача разработать линейку составов высококачественных бетонов (ВКБ), начиная от средних классов В40-B50 и заканчивая высокопрочными бетонами классов В80-В90, с комплексным использованием местного сырья, в том числе и техногенной природы.

Рецептуры ВКБ запроектированы марки по осадке конуса П5 (ОК $=22 \pm 2$ см) как широко распространенной в современном высотном монолитном строительстве и не требующей интенсивного виброуплотнения, а в некоторых случаях, позволяющей бетонировать без дополнительного уплотнения.

Составы и свойства высококачественных бетонных смесей повышенной сохраняемости и долговечности представлены в таблице 3.

Таким образом, с использованием местного природного и техногенного сырья проектированы оптимальные рецептуры высокоэффективных бетонных 
смесей с маркой по осадке конуса П5 и сохраняемостью более 8 часов для получения ВКБ.

Таблица 2 - Составы и свойства бетонных смесей на основе местного природного и техногенного сырья

\begin{tabular}{|c|c|c|c|c|c|c|c|c|c|c|c|c|c|c|}
\hline \multirow[b]{3}{*}{ 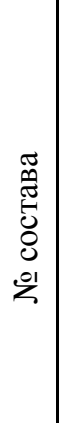 } & \multirow{3}{*}{ 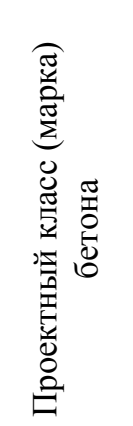 } & \multirow{3}{*}{ 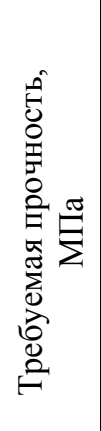 } & \multicolumn{8}{|c|}{ Расход компонентов бетонной смеси, кг/м³ } & \multicolumn{4}{|c|}{ Характеристики смеси } \\
\hline & & & \multicolumn{2}{|c|}{ Щебень } & \multirow{2}{*}{ 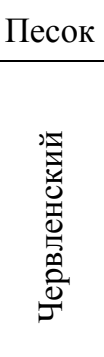 } & \multicolumn{2}{|c|}{ Вяжущее } & & \multicolumn{2}{|c|}{ Добавка } & \multirow[b]{2}{*}{$\underset{\oplus}{\vec{D}}$} & \multirow[b]{2}{*}{ 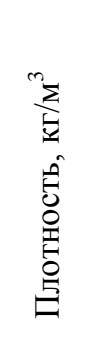 } & \multirow[b]{2}{*}{ 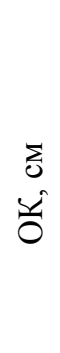 } & \multirow[b]{2}{*}{ 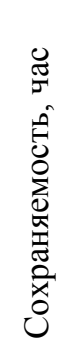 } \\
\hline & & & 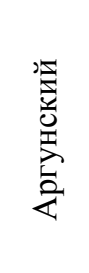 & $\begin{array}{l}25 \\
\frac{1}{5} \\
0 \\
0 \\
0 \\
0 \\
0 \\
0 \\
0 \\
0 \\
0\end{array}$ & & $\begin{array}{l}\stackrel{+}{+} \\
\dot{8} \\
\dot{0} \\
\stackrel{9}{1}\end{array}$ & 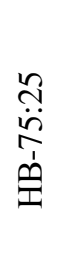 & 䍃 & 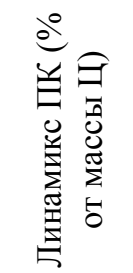 & 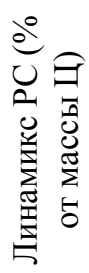 & & & & \\
\hline 1. & $\begin{array}{c}\mathrm{B} 30 \\
(\mathrm{M} 400)\end{array}$ & 39,3 & 1000 & - & 855 & 385 & - & 161 & $1,1(0,3)$ & $\begin{array}{c}2,5 \\
(0,7)\end{array}$ & 0,45 & 2398 & 23 & 7,0 \\
\hline 2. & $\begin{array}{c}\text { B40 } \\
(\mathrm{M} 500)\end{array}$ & 52,4 & 1000 & - & 795 & 435 & - & 158 & $1,3(0,3)$ & $\begin{array}{c}3,0 \\
(0,7)\end{array}$ & 0,36 & 2407 & 21 & 7,0 \\
\hline 3. & $\begin{array}{c}\mathrm{B} 45 \\
\text { (M600) }\end{array}$ & 58,9 & 1000 & - & 765 & 470 & - & 162 & $1,4(0,3)$ & $\begin{array}{c}3,3 \\
(0,7)\end{array}$ & 0,34 & 2427 & 23 & 8,0 \\
\hline 4. & $\begin{array}{c}\text { B55 } \\
\text { (M700) }\end{array}$ & 72,0 & - & $1000^{*}$ & 735 & - & 540 & 161 & $1,6(0,3)$ & $\begin{array}{c}3,8 \\
(0,7)\end{array}$ & 0,31 & 2451 & 23 & 8,5 \\
\hline 5. & $\begin{array}{c}\mathrm{B} 60 \\
(\mathrm{M} 800)\end{array}$ & 78,6 & - & $1000 *$ & 685 & - & 600 & 165 & $1,8(0,3)$ & $\begin{array}{c}4,3 \\
(0,7)\end{array}$ & 0,30 & 2462 & 21 & 9,0 \\
\hline 6. & $\begin{array}{c}\text { B80 } \\
\text { (M1000) }\end{array}$ & 104,7 & - & $1000^{*}$ & 620 & - & 700 & 170 & $2,1(0,3)$ & $\begin{array}{c}4,9 \\
(0,7)\end{array}$ & 0,32 & 2481 & 24 & 10,0 \\
\hline
\end{tabular}

Примечание: * - применялся обогащенный более прочный щебень фракции 5-20 мм с маркой по дробимости М1200;

На исследуемых нами составах ВКБ определялась прочность $R_{C Ж}^{1 c y m}, R_{C Ж}^{3 c y m}$, $R_{C Ж}^{7 c y m}$ и $R_{C Ж}^{28 c y m}$ с использованием контрольных образцов-кубов с ребром 10 см. Образцы до момента испытания выдерживали, как правило, в нормальновлажностных условиях $\left(\varphi=95 \pm 5 \%, \mathrm{t}=20 \pm 2{ }^{\circ} \mathrm{C}\right)$.

Призменная прочность на сжатие исследуемых нами составов ВКБ определялась в возрасте 28 суток на контрольных образцах-призмах размерами 100x100x400 мм.

Результаты испытаний разработанных ВКБ на основе техногенного сырья представлены в таблице 3 .

Таблица 3 - Свойства ВКБ на основе сырья различной природы

\begin{tabular}{|c|c|c|c|c|c|c|c|c|c|c|c|c|}
\hline \multirow{2}{*}{ 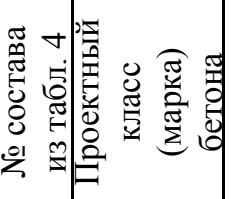 } & \multirow{2}{*}{ 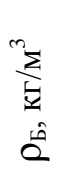 } & \multicolumn{2}{|c|}{$\begin{array}{c}\text { Прочность на сжатие в } \\
\text { возрасте ..., МПа }\end{array}$} & \multirow{2}{*}{$\frac{\approx}{\approx}$} & \multirow{2}{*}{$\stackrel{\overrightarrow{2}}{2}$} & \multirow{2}{*}{ 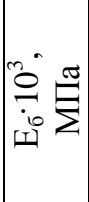 } & $\begin{array}{l}\text { Деформация } \\
\varepsilon, \text { мм/м }\end{array}$ & \multirow{2}{*}{ 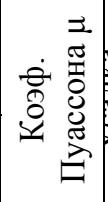 } & \multirow{2}{*}{$\begin{array}{ll}0 \\
0\end{array}$} & \multirow{2}{*}{ 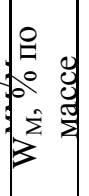 } & \multirow{2}{*}{3} & \multirow{2}{*}{ LI } \\
\hline & & $\mathrm{R}$ & $\mathrm{R}_{\Pi P}$ & & & & 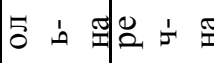 & & & & & \\
\hline
\end{tabular}




\begin{tabular}{|c|c|c|c|c|c|c|c|c|c|c|c|c|c|c|c|c|c|}
\hline & & & $\begin{array}{c}1 \\
\text { сут }\end{array}$ & $\begin{array}{c}3 \\
\text { сут }\end{array}$ & $\begin{array}{c}7 \\
\text { сут }\end{array}$ & $\begin{array}{l}28 \\
\text { сут }\end{array}$ & $\begin{array}{l}28 \\
\text { сут }\end{array}$ & & & & & & & & & & \\
\hline 1. & $\begin{array}{c}\text { B30 } \\
(\mathrm{M} 400)\end{array}$ & 2336 & 14,3 & 31,7 & 41,1 & 46,7 & 38,3 & 0,82 & 4,8 & 43,5 & 2,08 & 0,49 & 0,237 & 0,62 & 2,7 & W14 & F400 \\
\hline 2. & $\begin{array}{c}\text { B40 } \\
(\mathrm{M} 500)\end{array}$ & 2352 & 17,8 & 38,9 & 51,7 & 58,1 & 47,6 & 0,82 & 5,7 & 44,8 & 1,99 & 0,47 & 0,235 & 0,60 & 2,7 & W14 & F400 \\
\hline 3. & $\begin{array}{c}\text { B45 } \\
(\mathrm{M} 600)\end{array}$ & 2358 & 22,3 & 45,5 & 59,9 & 65,8 & 54,6 & 0,83 & 6,4 & 46,2 & 1,96 & 0,46 & 0,234 & 0,55 & 2,5 & W16 & F500 \\
\hline 4. & $\begin{array}{c}\text { B55 } \\
(\mathrm{M} 700)\end{array}$ & 2365 & 26,4 & 54,1 & 69,6 & 77,3 & 65,7 & 0,85 & 8,2 & 47,5 & 1,96 & 0,45 & 0,228 & 0,40 & 2,4 & W18 & F500 \\
\hline 5. & $\begin{array}{c}\text { B60 } \\
(\mathrm{M} 800)\end{array}$ & 2383 & 29,5 & 59,8 & 75,3 & 85,4 & 72,6 & 0,85 & 8,6 & 52,4 & 1,95 & 0,43 & 0,222 & 0,36 & 2,4 & W20 & F600 \\
\hline 6. & $\begin{array}{c}\text { B80 } \\
(\mathrm{M} 1000)\end{array}$ & 2408 & 40,9 & 81,8 & 106,1 & 115,3 & 99,2 & 0,86 & 9,7 & 54,5 & 1,90 & 0,40 & 0,210 & 0,31 & 2,2 & W20 & F600 \\
\hline
\end{tabular}

Из анализа таблицы 3 видно, что динамика набора прочности бетона на НВ заметно отличается от динамики роста прочности бетонов на ПЦ. Это хорошо видно на рисунке 1.

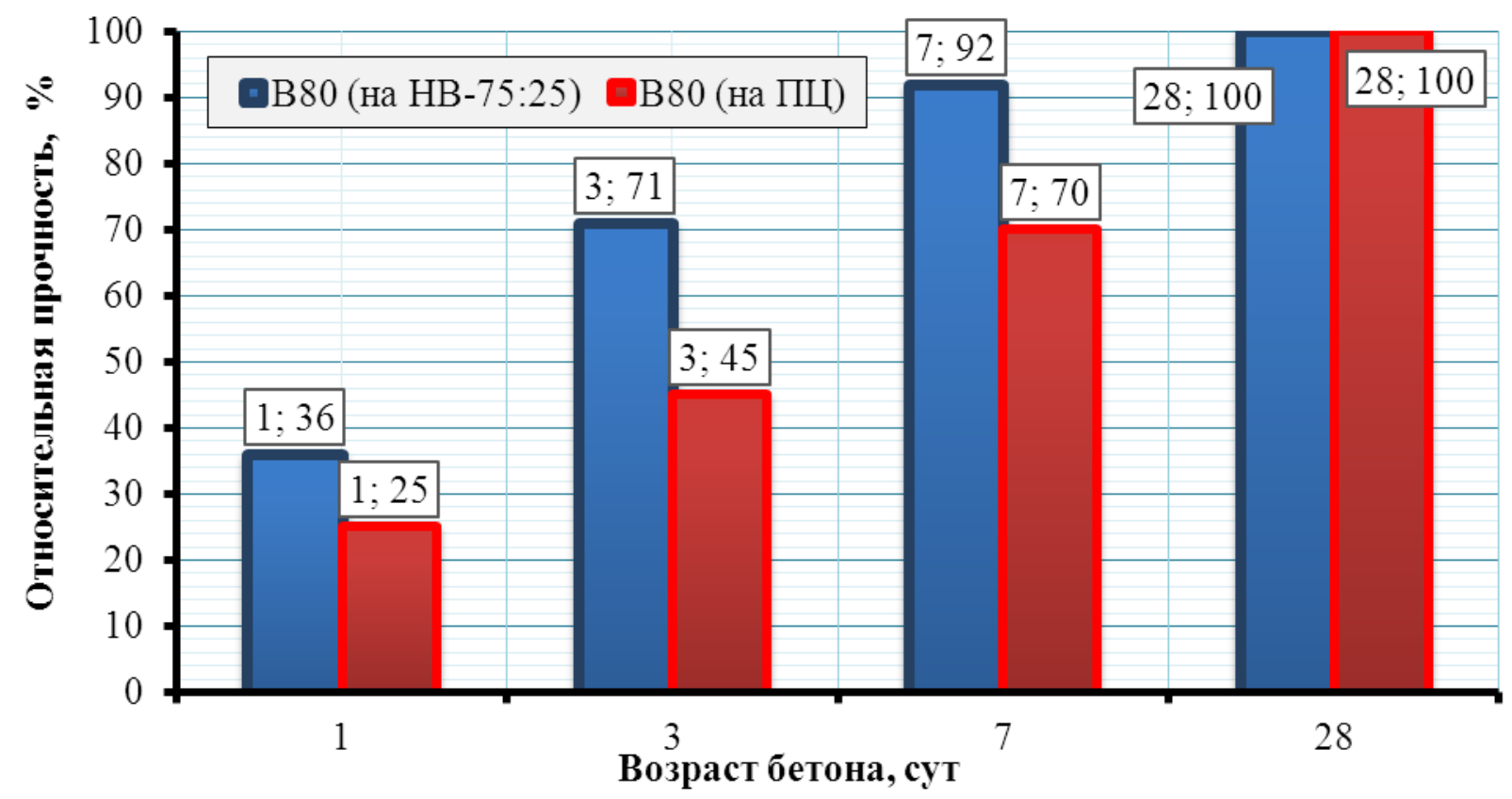

Рис. 1 - Оценка роста во времени прочностных характеристик бетона в зависимости от вида вяжущего

Установлено, что процесс набора прочности бетонов на НВ в раннем возрасте (1-3 сут) ускоряется в 1,5-2 раза. Так, бетон на НВ в возрасте 1 сут имеет прочность около 33-36 \% от проектного, а возрасте 3 сут - этот показатель достигает до 70 \%. 7-ми суточная прочность бетона, полученного с использованием НВ, составляет около 85-90 \% от проектного, что существенно выше показателей традиционных составов на обычном ПЦ. Эти показатели у бетонов на ПЦ в возрасте 1, 3 и 7 сут составляют около 24, 35 и 70 \% от 
проектной прочности соответственно. Такое явление заметно быстрого роста прочности у бетонов на НВ объясняется особенностью добавки Д-5, входящей в состав наполненного вяжущего в количестве $2 \%$ от его массы. Добавка Д-5, заметно увеличивающая подвижность бетонных смесей в первые часы ее приготовления (1-3 часа) благодаря своему пластифицирующему эффекту, уже в первые сутки в определенной степени переходит в роль «добавкиускорителя». Такая особенность данной добавки делает ее полифункциональной (комплексной).

Таким образом, разработаны и исследованы рецептуры наполненных вяжущих (НВ) с активностью 60-71 МПа с тонкодисперсными МНТП из бетонного лома и кирпичного боя с соотношением 70:30 \% соответственно, при этом доля смеси наполнителя в НВ составило 25 и $40 \%$ от массы вяжущего.

Предложены оптимальные рецептуры высококачественных бетонных смесей для высокопрочных бетонов с использованием местного природного и техногенного сырья с улучшенными технологическими и физикомеханическими свойствами для монолитного строительства.

\section{Исследование выполнено при финансовой поддержке РФФИ в рамках научного проекта № 18-48-200001.}

\section{Список литературы}

1. Баженов, Ю.М. Технология бетона, строительных изделий и конструкций [Текст] / Ю.М. Баженов, Л.А. Алимов, В.В. Воронин [и др.]. -М.: Изд-во АСВ, 2008. - $350 \mathrm{c}$.

2. Баженов, Ю.М. Мелкозернистые бетоны из вторичного сырья для ремонта и восстановления поврежденных зданий и сооружений [Текст]: научное издание / Ю.М. Баженов, Д.К-С. Батаев, Х.Н. Мажиев [и др.]. -Грозный: ИП «Султанбегова Х.С.», 2011. -342 с.

3. Каприелов, С.С., Шейнфельд, А.В., Дондуков, В.Г. Цементы и добавки для производства высокопрочных бетонов // Строительные материалы. 2017. -№ 11. -C. 4-10.

4. Батаев, Д.К-С. Рецептуры высокопрочных бетонов на техногенном и природном сырье / Д.К-С. Батаев, М.С. Сайдумов, Т.С-А. Муртазаева [и др.] // Актуальные проблемы современной строительной науки и образования: материалы Всероссийской научно-практической конференции, посвященной 60-летию строительного факультета ФГБОУ ВО «ГГНТУ им. акад. М.Д. Миллионщикова», 12-13 октября 2017 г. -Грозный: Бисултанова П.Ш., 2017. C.109-117.

5. Kuprina, A.A., Lesovik, V.S., Zagorodnyk, L.H., Elistratkin, M.Y. Anisotropy of materials properties of natural and man-triggered origin // Research Journal of Applied Sciences. 2014. -Vol. 9. -Issue 11. -PP. 816-819. 
6. Каприелов, С.С. Высокопрочный пневмобетон с добавкой микрокремнезема для защитных покрытий [Текст] / С.С. Каприелов, Н.Г. Булгакова // Бетон и железобетон. -1993. - №5. -С. 7-8.

7. Лесовик, В.С. Строительные композиты на основе отсевов дробления бетонного лома и горных пород [Текст]: научное издание / В.С. Лесовик, СА.Ю. Муртазаев, М.С. Сайдумов. -Грозный: МУП «Типография», 2012. - 192 с. 8. Афонина, М.И. Особенности строительства спортивных сооружений на территориях бывших промышленных зон [Текст] / М.И. Афонина, Е.В. Козырева // В сборнике: Дни студенческой науки. Сборник докладов научнотехнической конференции по итогам научно-исследовательских работ студентов института строительства и архитектуры. -2017. -С. 390-392.

9. Volodchenko, A.A., Lesovik, V.S., Zagorodnjuk, L.H., Volodchenko, A.N., Aleksandrovna, K.A. The control of building composite structure formation through the use of multifunctional modifiers // Research Journal of Applied Sciences 2016. 10(12). - C.931-936

10. Щербань, Е.M. Разработка состава пуццоланового цемента на вулканическом туфе [Текст] / Е.М. Щербань, С.А. Стельмах, А.К. Халюшев [и др.] // В сборнике: Строительство. Архитектура. Экономика. Материалы Международного форума "Победный май 1945 года": сборник статей. Министерство образования и науки Российской Федерации, Донской государственный технический университет, Профсоюз работников народного образования и науки Российской Федерации. -2018. -С. 110-113.

11. Муртазаев, С-А.Ю. Мелкозернистые бетоны на основе наполнителей из вторичного сырья [Текст]: научное издание / С-А.Ю. Муртазаев, Д.К-С. Батаев, 3.Х Исмаилова [и др.]. -М.: «Комтехпринт», 2009. -142 с.

12. Лермит, Р. Проблемы технологии бетона [Текст] / Р. Лермит. -М.: Издательство ЛКИ, 2007. -296 с.

13. Баженов, Ю.М. Технология бетона [Текст] / Ю.М. Баженов. - 3-е изд. -М.: ACB, 2011. $-500 \mathrm{c}$.

14. Удодов, С.А. Повторное введение пластификатора как инструмент управления подвижностью бетонной смеси // Сборник научных трудов Кубанского государственного технологического университета. -2015. -№9. -С. 175-185.

15. Mintsaev M.Sh., Bataev D. K.-S., Mazhiev K. Kh., Mazhiev Adam Kh., Mazhieva A. Kh., Mazhiev Aslan Kh., Mazhiev M.Kh. Prospects for Using 3DPrinting Technologies in Construction of Buildings in Seismic Areas. Advances in Engineering Research, volume 177, International Symposium on Engineering and Earth Sciences (ISEES 2018). -PP. 311-315.

16. Стельмах, С.А. Влияние некоторых характеристик применяемого крупного заполнителя на свойства тяжелого бетона, предназначенного для изготовления центрифугированных изделий и конструкций [Текст] / С.А. Стельмах, Е.М. Щербань, К.В. Сердюков [и др.] // Вестник Белгородского государственного технологического университета им. В.Г. Шухова. -2017. -№ 10. -С. 15-20. 
17. Корянова, Ю.И., Резанцев, Н.Е., Шумилова, А.С. Материалы и конструкции, используемые при строительстве высотных зданий - от традиций к новшествам // Аллея науки. 2018. -Т.6. -№ 4 (20). -С.95-99.

18. Солдатов, А.А. Опыт использование силиката натрия в качестве вяжущего веществе в производстве строительных материалов [Текст] / А.А. Солдатов, А.В. Галыч, И.В. Сариев [и др.] // В сборнике: Актуальные проблемы строительства, транспорта, машиностроения и техносферной безопасности. Материалы IV-й ежегодной научно-практической конференции СевероКавказского федерального университета. Н.И. Стоянов (ответственный редактор). -2016. -С. 186-188.

19. Усов, Б.А. Физико-химические процессы строительного материаловедения в технологии бетона и железобетона [Текст]: учеб. пособие для студентов по специальности 270106 «Производство строительных материалов, изделий и конструкций» / Б.А. Усов. -М.: Издательство МГОУ, 2009. -326 с.

20. Salamanova, M.Sh. Clinker-free binders based on finely dispersed mineral components / Murtazaev S.A.Yu., Salamanova M.Sh. // B сборнике: ibausil conference proceedings. -2018. -C. 707-714.

21. Self-Consolidating Concretes with Materials of the Chechen Republic and Neighboring Regions / Madina Salamanova, Magomed Khubaev, Magomed Saidumov, Tamara Murtazayeva // International journal of environmental \& science education. -2017. - Vol.11. -№18. -PP.12719-12724. 